\title{
SCLC Degradation in 980 nm Pump Laser by Using Electrical Noise
}

\author{
B. Orsal ${ }^{1}$ and I. Asaad ${ }^{2}$ \\ ${ }^{1}$ Centre d'Electronique et de Microoptoélectronique de Montpellier (CEM2), Université Montpellier II, \\ 34095 Montpellier Cedex 5, France \\ ${ }^{2}$ HIRLA, Damascus University, 99 Damascus, Syria
}

Correspondence should be addressed to I. Asaad, imad.asaad@contact.asso.fr

Received 16 November 2011; Accepted 5 December 2011

Academic Editors: R. Jäger and D.-N. Wang

Copyright ( $) 2012$ B. Orsal and I. Asaad. This is an open access article distributed under the Creative Commons Attribution License, which permits unrestricted use, distribution, and reproduction in any medium, provided the original work is properly cited.

The knowledge of the noise levels is important for pump laser diodes as it allows to study and to locate the noise sources and their origin. $980 \mathrm{~nm}$ fresh and aged pump lasers have been characterized by using electrical noise measurements. At $10 \mathrm{~Hz}$, the spectra are dominated by $1 / f^{m}(1 \leq m \leq 2)$ noise. Current noise spectral density (CNSD) is dominated by $I_{L}^{m}(1<m \leq 2)$. The trapping defect density near the $\mathrm{n}^{+} \mathrm{n}^{-}$and $\mathrm{p}^{+} \mathrm{p}^{-}$interfaces is related to pinching of the space-charge-limited current (SCLC) effect. An excess electrical noise due to longitudinal mode hopping is correlated with optical power fluctuations.

\section{Introduction}

In this work, we present the electrical noise at low frequency for fresh pump laser diodes emitting at $980 \mathrm{~nm}$ (reference laser), and we study the parametric evolution and the defects generated in aged $980 \mathrm{~nm}$, stressed during $400 \mathrm{hrs}$ at $50^{\circ} \mathrm{C}$ and high current injection (500 mA) (aged laser).

\section{Device Description}

The device used in this study is a conventional ridge waveguide AlGaAs/InGaAs pump laser with a GRIN-SCH (Graded Index Separate Confinement Heterostructure) and a Single Quantum Well (SQW) $\left(\mathrm{p}^{+} \mathrm{p}^{-}, \mathrm{n}^{+} \mathrm{n}^{-}\right)$emitting at $980 \mathrm{~nm}$. The laser has a cavity length of $1200 \mu \mathrm{m}$ and is coated, for the $50^{\circ} \mathrm{C}$ aging tests, with standard low-

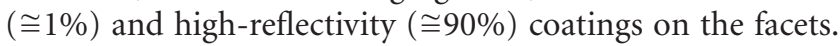
A different coating reflectivity and aging configuration has also been studied in a previous work [1-3].

\section{Static Characteristic of the Pump Laser Diode}

From the static analysis, current laser versus externally applied voltage $I_{L}\left(V_{L}\right)$, we then deduce in Figure 1 the evolution of the differential resistance $R_{d}=d V_{L} / d I_{L}$. The $R_{d}\left(I_{L}\right)$ characteristic recorded after $400 \mathrm{~h}$ of aging under a stress at $50^{\circ} \mathrm{C}$ and high current density injection (500 mA) was compared with the same laser diode before aging.

Before threshold, differential resistance is proportional to $I_{L}^{-1}$; above threshold current $\left(I_{L}>18 \mathrm{~mA}\right), R_{d}$ decreases to $I_{L}^{-1 / 2}$. This phenomenon is usually observed when the carriers are injected from high doping material to low doping material. In our structure, the carriers are injected from $\mathrm{n}^{+}$or $\mathrm{p}^{+}$into $\mathrm{n}^{-}$or $\mathrm{p}^{-}$.

The physical phenomenon can be explained in Figure 2. The $\mathrm{p}^{+} \mathrm{p}^{-}$and $\mathrm{n}^{+} \mathrm{n}^{-}$interfaces form space charge regions. The carriers are prevented to go into quantum well by the two space charge effects; then, the carrier injection is associated to space-charge-limited current effect (SCLC) $[4,5]$.

Consider the relation of Mott-Gurney:

$$
I_{L, \mathrm{SCLC}}=\frac{9 \varepsilon \varepsilon_{0} \mu}{8 L^{3}} V^{2}
$$

where $\varepsilon$ is the dielectric constant, $\varepsilon_{0}$ the free space permitivity, $L$ the junction thickness, and $\mu$ the carriers mobility. 


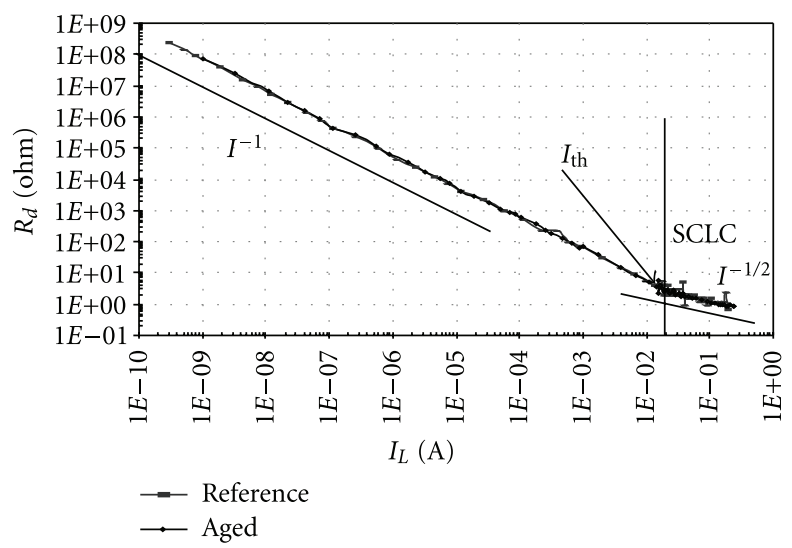

FIGURE 1: Dynamic resistance $R_{d}$ versus laser current $I_{L}$.

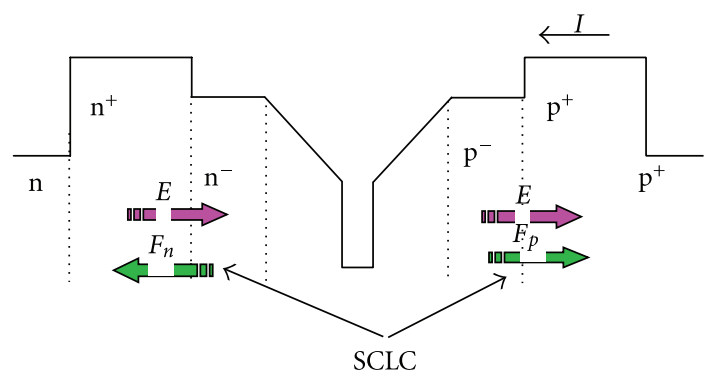

FIGURE 2: Space-charge-limited current effect observed in the laser layers.

We then deduce the evolution of the differential resistance $R_{d}=d V_{L} / d I_{L}$ :

$$
R_{d}=\frac{1}{2} \cdot \frac{1}{\sqrt{9 \varepsilon \varepsilon_{0} \mu / 8 L^{3}}} \cdot \frac{1}{\sqrt{I_{L, S C L C}}} .
$$

The typical evolution of the electrical and optical parameters is shown in Table 1.

We show that the static characteristics do not allow making difference between the aged laser and the reference laser. This difference can be made with electrical noise measurements.

\section{Low-Frequency Noise Measurements}

4.1. Noise Equivalent Circuit. In order to obtain a better analysis of the behavior of the devices studied, it is necessary to give the noise equivalent circuit of multimode laser diode (4 modes for this Pump laser) at low frequency (Figure 3).

This circuit is obtained by deriving the rate equations including Langevin white noise sources and $1 / f$ noise sources describing in [6], and we are considering all other noise sources to be produced by the interfaces and the trapping defect density [7].

Where $R$ is a differential diode resistance, $R_{\text {sek }}$ is an additional resistance due to coupling of spontaneous emission into lasing mode for $k$ mode, $v_{\text {nek }}$ is a voltage noise source due to the fluctuation of the photon population, and $i_{n}$ is the

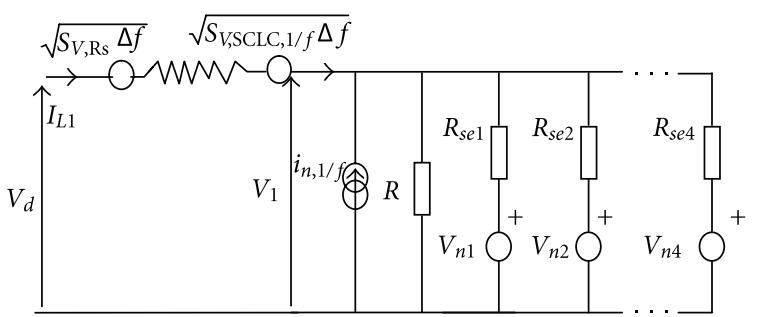

FIgURE 3: Noise equivalent circuit of a multimode laser diode at low frequency.

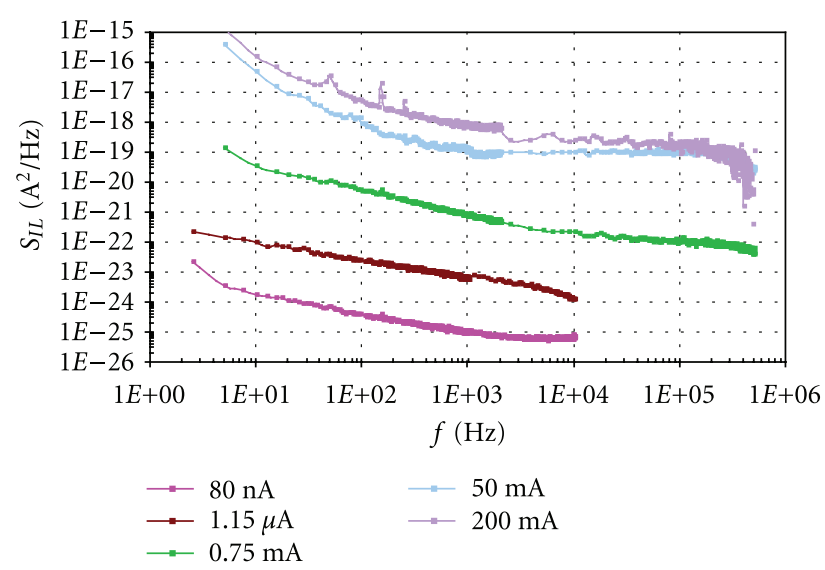

Figure 4: Current noise spectral density versus frequency.

current noise source due to the fluctuation of the electron population. The input signal is the modulation current $i_{L 1}$ or the modulation voltage $v_{1}$ for intrinsic circuit; $S_{V, R_{s}}=$ $\left(\alpha I_{L} / f \tau_{s}\right) R_{s}^{2}$ is the thermal noise due to series resistance $R_{s} ; S_{V \text {,SCLC }}$ is the noise source due to space-charge-limited current effect.

4.2. Current Noise Spectral Density (CNSD). We make a noise analysis by Fast Fourier Transform FFT measurements and very low-noise amplifier. The Current Noise Spectral Density (CNSD) $S_{i L}$ represents the current intensity fluctuations at $20 \pm 0,1^{\circ} \mathrm{C}$. The CNSD has been measured over a wide frequency range from $1 \mathrm{~Hz}$ to $1 \mathrm{MHz}$; we give in Figure 4 a typical noise spectrum: $1 / f^{m}(1 \leq m \leq 2)$ decreases followed by flat noise level.

Figure 5 exhibits the low-frequency current noise measured at $10 \mathrm{~Hz}$, as a function of the laser current. We notice that the spectra are dominated by $1 / f$ (flicker) noise due to the carrier mobility fluctuations given by TGM Kleinpenning's model [8]; the CNSD varies as $I_{L}^{2}$ :

$$
S_{I L I}=\frac{\alpha_{\mathrm{H}} I_{L}^{2}}{f N},
$$

with $\alpha_{\mathrm{H}}$ being Hooge parameter, $N$ being free carrier number, and $f$ being frequency. 
TABLE 1: Evolution of the electrical and optical parameters.

\begin{tabular}{lcccc}
\hline Laser diode & $\begin{array}{c}R_{s}\left(\text { for } I_{L}=100 \mathrm{~mA}\right) \\
\text { (Series resistance) }\end{array}$ & $I_{\text {th }}$ (Threshold current) & $\begin{array}{c}P_{\text {opt }} \text { at } I_{L}=200 \mathrm{~mA} \\
\text { (Optical power) }\end{array}$ & $\eta$ (Efficiency) \\
\hline Reference & $1 \mathrm{ohm}$ & $17.5 \mathrm{~mA}$ & $220 \mathrm{~mW}$ & $90 \%$ \\
Aged & $1 \mathrm{ohm}$ & $17.5 \mathrm{~mA}$ & $215 \mathrm{~mW}$ & $88 \%$ \\
\hline
\end{tabular}

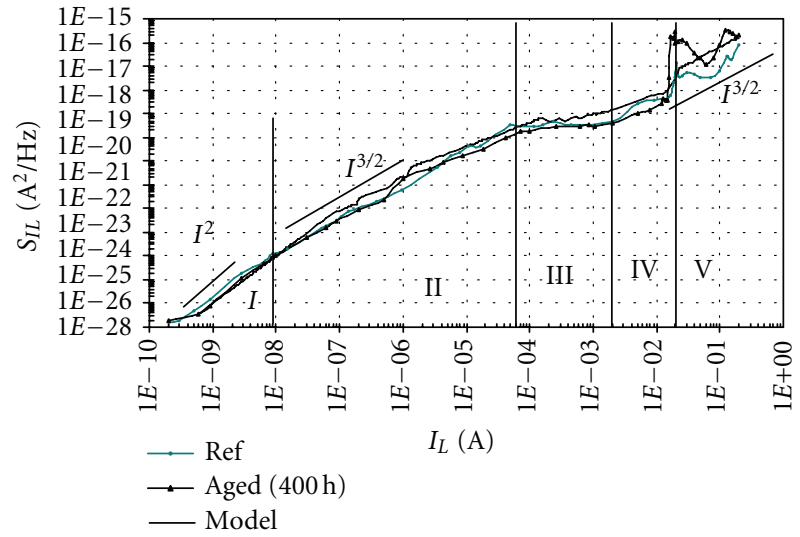

FIGURE 5: Electrical noise spectral density $S_{I L}$ at $10 \mathrm{~Hz}$ versus $I_{L}$.

In this case, we can calculate $\alpha_{\mathrm{H}}$ (Hooge parameter) at very weak current, $f=10 \mathrm{~Hz}, I=1 \mathrm{nA}$, and we found [9] that

$$
\alpha_{\mathrm{H}}=f \cdot \frac{S_{i, 1 / f}}{I^{2}} \frac{L^{2}}{q \mu R}=8,5 \cdot 10^{-4},
$$

where

$$
N=\frac{L^{2}}{q \mu R}
$$

$L=1200(\mu \mathrm{m})$ is the sample length, $q=1,6 \cdot 10^{-19}(C)$ is the elementary charge, $\mu=11000\left(\mathrm{~cm}^{2} \mathrm{~V}^{-1} \cdot \mathrm{S}^{-1}\right.$ at $300 \mathrm{~K}$ for $\mathrm{AlGaAs} / \mathrm{InGaAs}$ ) is the carrier mobility, and $R=10^{8} \Omega$ is the dynamic resistance. The $\alpha_{\mathrm{H}}$ value is in agreement with those given by Hooge for AlGaAs/InGaAs at $300 \mathrm{~K}$ [10].

Region II. At $10 \mathrm{~Hz}$, the CNSD varies as $I_{L}^{3 / 2}$, it can be explained by fluctuations of diffusion current, and, it is due to the traps placed near the $\mathrm{n}^{+} \mathrm{n}^{-}$and $\mathrm{p}^{+} \mathrm{p}^{-}$interfaces [4]. Then,

$$
S_{I L(10 \mathrm{~Hz})}=C(N, A) \cdot \frac{I_{L}^{3 / 2}}{f}=\frac{I_{L} V_{j}}{R_{L}} \sum_{i} \frac{D_{i} \tau_{i}}{\left(1+\omega_{i}^{2} \tau_{i}^{2}\right)},
$$

where $C(N, A)$ is the coefficient that depends on the section and on the number of free carriers, $R_{L}$ is junction resistance of $\mathrm{n}^{+} \mathrm{n}^{-}$and $\mathrm{p}^{+} \mathrm{p}^{-}$interfaces, $V_{j}$ is the applied voltage of junction, $D_{i}$ is a statistic factor, depending on the material, and $\tau_{i}$ is the recombination time.

This noise is related to pinching of the space-chargelimited current SCLC effect superposed with the noise due to fluctuations of current in the MQW outside the space charge region [11].
Region III. At $10 \mathrm{~Hz}$, we observe saturation of CNSD, the CNSD as predicted by Vandamme and Ruyven, when the laser current is lower than the threshold current $I_{\text {th }}$ [12], because series resistance $R_{s}$, in this region, is not neglected in comparison with differential resistance $R_{d}$ [13].

Regions $I V$ and $V$. The CNSD increases at $10 \mathrm{~Hz}$, due to the optical gain fluctuations in the active layer related to increase of number of photons around threshold $[14,15]$. In this case modeling is given by

$$
\begin{aligned}
S_{i d, 1 / f}= & \frac{2 \cdot Z^{2} \sum_{k=1}^{4} \sum_{l=2}^{4}\left(S_{V n k, V n l} / R_{\mathrm{Sek}}^{2}\right)}{\left(Z+R_{L}+R_{s}\right)^{2}} \\
& +\frac{R_{s}^{2}\left(q \alpha I_{L} / f \tau_{s}\right)+R_{L} I_{L} V_{j} \sum_{i}\left(D_{i} \tau_{i} /\left(1+\omega_{i}^{2} \tau_{i}^{2}\right)\right)}{\left(Z+R_{L}+R_{s}\right)^{2}}
\end{aligned}
$$

where $Z$ is the equivalent impedance of intrinsic circuit, $S_{V n k, V n l}$ is the noise source giving an excess noise due to longitudinal mode hopping which is related to output power fluctuations (exchange of power between two voltage noise sources due to the fluctuation of the photon population), $\tau_{i}$ is related to trap noise generators placed in the intrinsic layer and near $\mathrm{n}^{+} \mathrm{n}^{-}$and $\mathrm{p}^{+} \mathrm{p}^{-}$interfaces which absorb many photons in the aged active layer, and the end term of (7), in region $\mathrm{V}$, becomes dominant.

Region $V$. At $10 \mathrm{~Hz}$, the level of noise shows also that a proportionality of about $S_{i 10 \mathrm{~Hz}} \propto I^{3 / 2}$ originates to the traps in the vicinity of the $\mathrm{n}^{-} \mathrm{n}^{+}$and $\mathrm{p}^{-} \mathrm{p}^{+}$related to SCLC effect.

The CNSD in the aged laser is higher than that in the fresh laser; it is due to active layer degradation due to decrease of recombination time $\tau_{i}$.

\section{Summary}

The study of the electrical noise that represents the fluctuations of current at low frequency is very significant of degradation of the active layer. The spectra are dominated by conventional $1 / f$ (flicker) noise at weak current and the CNSD at $10 \mathrm{~Hz}$ is dominated by $I^{3 / 2}$. Pinching of the Space Charge shows limited current SCLC effect.

The defect is associated with carrier transport controlled by the $\mathrm{n}^{+} \mathrm{n}^{-}$and $\mathrm{p}^{+} \mathrm{p}^{-}$interfaces and the trapping defect density. An excess electrical noise due to longitudinal mode hopping is related with output optical fluctuations at low frequency. The CNSD in the aged laser is higher than that in the fresh laser, certainly due to the degradation of recombination time $\tau_{i}$. 


\section{References}

[1] M. Bettiati, C. Starck, M. Pommies et al., "Gradual degradation in $980 \mathrm{~nm}$ InGaAs/AlGaAs pump lasers," Materials Science and Engineering B, vol. 91-92, pp. 486-490, 2002.

[2] B. Orsal, J. M. Peransin, P. Signoret, and K. Daulasim, "Low frequency noise of a $980 \mathrm{~nm} \mathrm{InGa}-\mathrm{As} / \mathrm{GaAs}$ strained quantum well laser," Journal de Physique III, pp. 1739-1749, 1993.

[3] I. Asaad, B. Orsal, J. P. Perez et al., "Characterizations of 980 nm aged pump laser by using electrical and optical noise," in Proceedings of the 17th International Conference on Noise and Fluctuations (ICNF '03), p. 409, Prague, Czech Republic, August 2003.

[4] P. Balco, J. M. Peransin, B. Orsal, and Th. Ducourant, "Tempereture dependence of noise characteristcs in the PIN hydrogenated amorphous silicon switching diodes," in Proceedings of the 14th International Conference on Noise and Fluctuations (ICNF '97), Photonics West, leuven, Belgium, 1997.

[5] E. von Hauff, J. Parisi, and V. Dyakonov, "Field effect measurements on charge carrier mobilities in various polymerfullerene blend compositions," Thin Solid Films, vol. 511-512, pp. 506-511, 2006.

[6] B. Orsal, P. Signoret, J. M. Peransin, K. Daulasim, and R. Alabedra, "Correlation between electrical and optical photocurrent noises in semiconductor laser diodes," IEEE Transactions on Electron Devices, vol. 41, no. 11, pp. 21512161, 1994.

[7] C. Harder, J. Katz, S. Margalit, J. Shacham, and A. Yariv, "Noise equivalent circuit of a semiconductor laser diode," IEEE Journal of Quantum Electronics, vol. QE-18, no. 3, pp. 333-337, 1982.

[8] T. G. M. Kleipenning, "1/f noise in pn junction diodes," Journal of Vacuum Science \& Technology A, vol. 3, no. 1, pp. 185-191, 1985.

[9] F. N. Hooge, "1/f noise in semiconductor materials," in Proceedings of the 18th International Conference on Noise in Physical Systems and 1/f Fluctuations, V. Bareikis and R. Katilius, Eds., pp. 8-13, Lithuania, Palanga, 1995.

[10] L. K. J. Vandamme, S. Kibeya, B. Orsal, and R. Alabedra, " $1 / f$ noise and thermal noise of $\mathrm{As} / \mathrm{Al}_{0.4} \mathrm{Ga}_{0.6}$ As superlattice," in Proceedings of the InternationalConference on Noise in Physics Systems and 1/f Fluctuations, pp. 324-328, American Institute of Physics, New York, NY, USA, 1993.

[11] S. Kibeya, B. Orsal, R. Alabedra, and L. K. J. Vandamme, "Noise in superlatice avalanche photo-diodes," in Proceedings of the International Conference on Noise in Physics Systems and 1/f Fluctuations, pp. 325-329, Kyoto, Japan, November 1991.

[12] L. K. J. Vandamme and L. J. V. Ruyven, "1/f noise used as reliability test for laser diode," in Proceedings of the International Conference on Noise in Physical Systems and $1 / f$ Fluctuations, pp. 245-247, NewYork, NY, USA, 1983.

[13] B. Orsal, P. Signoret, J. M. Peransin, K. Daulasim, and R. Alabedra, "Correlation between electrical and optical photocurrent noises in semiconductor laser diodes," IEEE Transactions on Electron Devices, vol. 41, no. 11, pp. 21512161, 1994.

[14] R. J. Fronen and L. K. J. Vandamme, "“Low frequency intensity noise in semicoductor laser," IEEE Journal of Quantum Electronics, vol. 24, no. 5, pp. 724-736, 1988.

[15] Y. Zhu, E. Cabrera-Granado, O. G. Calderon et al., "Competition between the modulation instability and stimulated Brillouin scattering in a broadband slow light device," Journal of Optics, vol. 12, no. 10, Article ID 104019, 2010. 

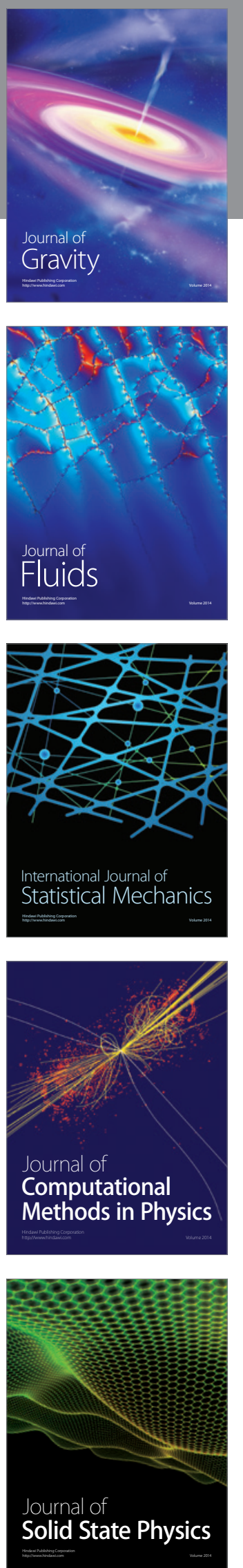
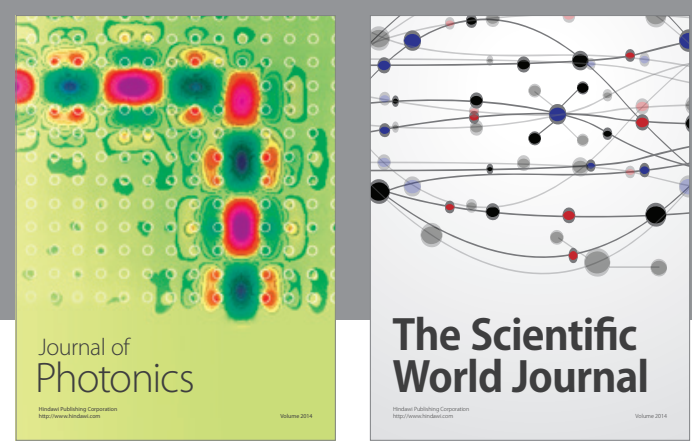

The Scientific World Journal

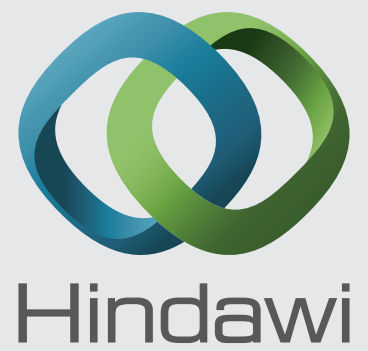

Submit your manuscripts at http://www.hindawi.com
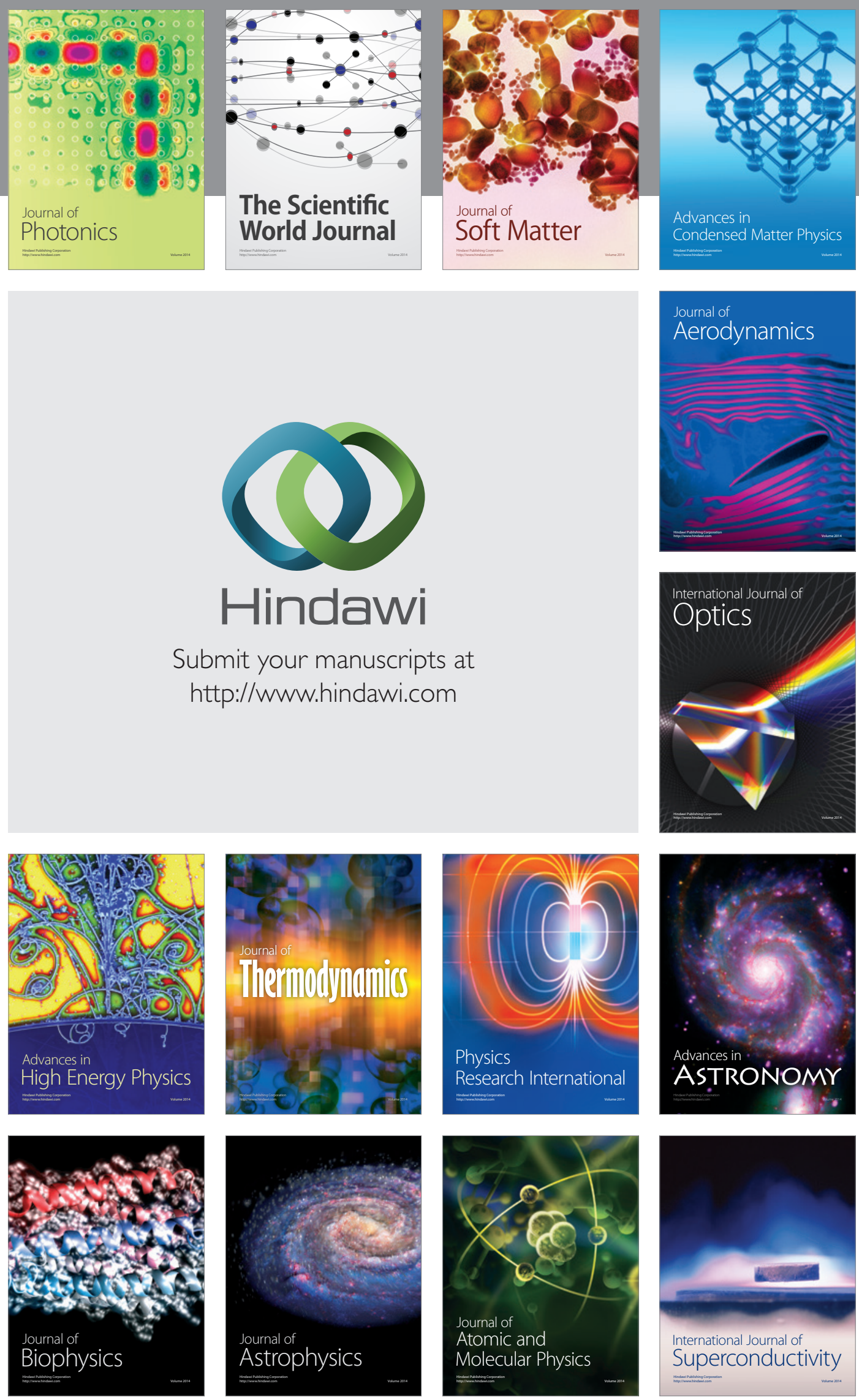
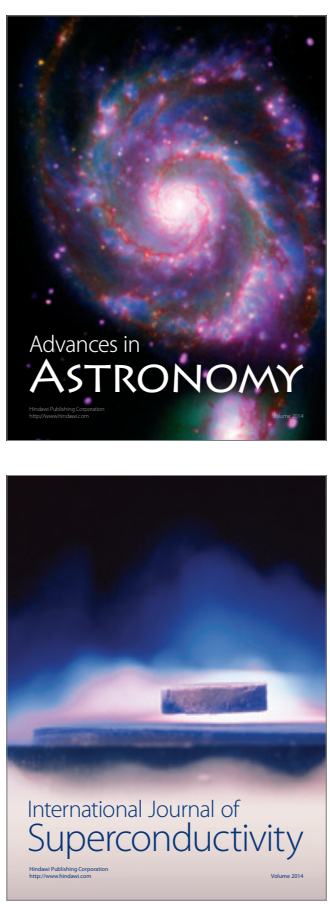